\title{
Onion Planting by Direct Seeding into the Fields
}

\author{
Aurica SOARE ${ }^{*}$, Gheorghe VOICU ${ }^{1}$ \\ Braila Faculty of Engineering, 29 Calea Călăraşilor Street, Brăila, "Dunărea de Jos" University of Galati, \\ 47 Domnească Street; \\ * corresponding author: aurica.soare@gmail.com \\ Bulletin USAMV series Agriculture 71(2)/2014 \\ Print ISSN 1843-5246; Electronic ISSN 1843-5386 \\ DOI 10.15835/buasvmcn-agr: 10340
}

\begin{abstract}
Determine some quantitative and qualitative elements of the dry bulbs production in order to establish the suitability of the best cultivar, due to the fact that the soil characteristics influence for sure the success of the onion crop planted directed onto the field.

The biological material was represented by the Diamant (n.t. Diamante in English) aborigine type and the Dutch hybrid Daytona. The crops were created in Braila county, on a typical chernozeme type of soil with physical and chemical characteristics which are favorable to creating the onion crop (the apparent density $1,18 \mathrm{~g} / \mathrm{cm}^{3}$; pH 7,91; humus 3,27\%) through direct seeding, the experimental variants being placed in store blocks without randomization, the experimental area being of 480 square meters.

The average percentage of emergence was $85,70 \%$ at Daytona and $81,30 \%$ at Diamant type, but the density at harvesting is $84,2 \%$ at Daytona and $79,7 \%$ at Diamant. In what concerns the average weight of the onion bulbs with a diameter over $30 \mathrm{~mm}$ was 51,84 g at Daytona and 53,68 g at Diamant. In connection to the quality of the bulbs at Daytona, the bulbs with a diameter over $30 \mathrm{~mm}$ were in a percentage of $90,8 \%$, and at Diamant in a percentage of $73,4 \%$. The productions obtained were $41,40 \mathrm{t} / \mathrm{ha}$ at Daytona and 33,52 t/ha at Diamant.

Following to the determinations performed, it is observed that for these two cultivars analyzed, the productions obtained were over $30 \mathrm{t} / \mathrm{ha}$, with an extra difference of 7,8 $\mathrm{t} / \mathrm{ha}$ at Daytona hybrid which excelled also at a better uniformity of the bulbs.
\end{abstract}

Keywords: cultivar, density, hybrid, production, emergence

Introduction: In our country, the onion crop is on the third place among the vegetable species, after tomatoes and cabbage, with an area of over 35 thousand ha. In the last years, it has been observed a reduction of the areas cropped with onion through chive and the production has been oriented towards the technology of onion planting by direct seeding into the field, following to the fact that the producers have competitive equipments for setting up, taking care of and harvesting the onion crops; there are many hybrids that are suited for this kind of crop and herbicides and fungicides have been created in order to allow an efficient control of the weeds and maintaining a very good phytosanitary status of the crop.

The increase of the carbon dioxide concentration into the soil, at roots level, due to the crust which is formed on the surface, results into water and mineral salts absorption inhibition, a process that will maintain later on after it would be ensured air input through soil aeration. (Ramirez H., Rodriguez 0., 1997).

The onion is cropped on fields that are soft, fertile, with good water retention, well drained, with favorable exposure, with a low degree of weeds, with pH 5,8-6,5 (Ugas R. et al, 2000).

Aims: Determine some quantitative and qualitative elements of the dry bulbs production in order to establish the suitability of the best cultivar, due to the fact that the soil characteristics influence for sure the success of the onion crop planted directed onto the field.

Materials and methods: The biological material was represented by the Diamant (n.t. Diamante in English) aborigine type and the Dutch hybrid Daytona.

Diamant is a semi out of season type, with 140$150 \mathrm{~g}$ bulbs average weight, without resistance to or 
tolerance at the attack of specific diseases, with 40 $45 \mathrm{t} / \mathrm{ha}$ production potential. Daytona is a hybrid resistant to Fusarium and tolerant at roots pink rot, with a very well developed root system, with 90-100 $g$ bulbs average weight and 55-60 t/ha production potential.

The crops characteristics are favorable to creating the onion crop (the apparent density $1,18 \mathrm{~g} / \mathrm{cm}^{3}$; $\mathrm{pH} \mathrm{7,91;} \mathrm{humus} \mathrm{3,27 \% )} \mathrm{through}$ direct seeding, the experimental variants being placed in store blocks without randomization, the experimental area being of 480 square meters.

The preceding plant was the tomato, a vegetable species considered a good preceding plant for the onion crop. The germinal bed had been prepared in autumn and finalized in the spring when the purpose was to break the crust and the aeration on 4-5 cm depth. The seeding was done in a un-modeled field, in the first decade of March, the seeding scheme being 5 rows with a distance between them of $250 \mathrm{~mm}$, between the seeds on the row of $3 \mathrm{~cm}$, ensuring an average number of seeds per hectare of 1100 000. During vegetation period which had lasted 155 days, there had been performed works for fighting against weeds, fertilizations phase wise; phytosanitary protection was ensured and 4 irrigations had been performed.

Results and Discussion: The emergence crop density was established for the bulk crop emergence, as it represented one of the most important elements of the productivity, its size influencing directly proportional the size of the productions obtained.

The average percentage of emergence was $85,70 \%$ at Daytona and $81,30 \%$ at Diamant type, but the density at harvesting is $84,2 \%$ at Daytona and $79,7 \%$ at Diamant, between these two cultivars existing a difference of $4,4 \%$ in what concerns the density at emergence and of $4,5 \%$ at the density at harvesting.

In what concerns the morphological characters of the bulbs (the diameter and height), there are some differences between Diamant and Daytona, accordingly: at Diamant, the average bulbs diameter is $5,6 \mathrm{~cm}$ and the height $6,2 \mathrm{~cm}$, and at Daytona, the average diameter is $6,2 \mathrm{~cm}$ and the diameter $7,3 \mathrm{~cm}$, resulting that the bulbs form is different; at Diamant, it is a flat spherical form, and at Daytona, elongated spherical form.

In what concerns the average weight of the onion bulbs with a diameter over $30 \mathrm{~mm}$, the average weight was 51,84 g at Daytona and 53,68 $\mathrm{g}$ at Diamant. In connection to the quality of the bulbs at Daytona, the bulbs with a diameter over $30 \mathrm{~mm}$ were in a percentage of $90,8 \%$, and at Diamant in a percentage of $73,4 \%$. The productions obtained were 41,40 t/ha at Daytona and 33,52 t/ ha at Diamant.

Conclusion. In conclusion, it can be said that these two cultivars analyzed are characterized by increased production, even through at Daytona the bulbs average weight was smaller than Diamant, the production obtained was higher at Daytona, not only due to a better emergence density, but also due to the higher degree of bulbs uniformity.

\section{REFERENCES}

1. Ramirez H., Rodriguez 0. (1997) Evaluation of some physical and chemical parameters of a soil under an onion crop International Symposium on Edible Alliaceae, ISHS Acta Horticulturae 433

2. Ugas R. et al (2000) Hortalizas datos basicos Universidad Nacional Agraria la Molina, Lima 